\title{
BMJ Open Can a midwife-led continuity model improve maternal services in a low- resource setting? A non-randomised cluster intervention study in Palestine
}

\author{
Berit Mortensen, ${ }^{1,2}$ Mirjam Lukasse, ${ }^{3,4}$ Lien My Diep, ${ }^{5}$ Marit Lieng, ${ }^{2,6}$ \\ Amal Abu-Awad, ${ }^{7}$ Munjid Suleiman, ${ }^{8}$ Erik Fosse ${ }^{1,2}$
}

To cite: Mortensen B,

Lukasse M, Diep LM, et al. Can a midwife-led continuity model improve maternal services in a low-resource setting? A nonrandomised cluster intervention study in Palestine. BMJ Open 2018;8:e019568. doi:10.1136/ bmjopen-2017-019568

\section{- Prepublication history for} this paper is available online. To view these files, please visit the journal online (http://dx.doi org/10.1136/bmjopen-2017019568).

Received 12 September 2017 Revised 25 January 2018 Accepted 14 February 2018

\section{Check for updates}

${ }^{1}$ The Intervention Centre, Oslo University Hospital, Oslo, Norway ${ }^{2}$ Institute for Clinical Medicine, Faculty of Medicine, University of Oslo, Oslo, Norway

${ }^{3}$ Faculty of Health Sciences, Oslo Metropolitan University, Oslo, Norway

${ }^{4}$ Faculty of Health and Social Sciences, University College of Southeast Norway, Oslo, Norway ${ }^{5}$ Oslo Centre for Biostatistics and Epidemiology, Oslo University Hospital, Oslo, Norway ${ }^{6}$ Department of Gynaecology, Oslo University Hospital, Oslo, Norway

${ }^{7}$ Department of Education in Health, Palestinian Ministry of Health, Nablus, Palestine

${ }^{8}$ Department of Statistics,

Palestinian Ministry of Education and Higher Education, Ramallah, Palestine

Correspondence to Berit Mortensen; beritmor@me.com

\section{ABSTRACT}

Objectives To improve maternal health services in rural areas, the Palestinian Ministry of Health launched a midwifeled continuity model in the West Bank in 2013. Midwives were deployed weekly from governmental hospitals to provide antenatal and postnatal care in rural clinics. We studied the intervention's impact on use and quality indicators of maternal services after 2 years' experience.

Design A non-randomised intervention design was chosen. The study was based on registry data only available at cluster level, 2 years before (2011and2012) and 2 years after (2014and2015) the intervention.

Setting All 53 primary healthcare clinics in Nablus and Jericho regions were stratified for inclusion.

Primary and secondary outcomes Primary outcome was number of antenatal visits. Important secondary outcomes were number of referrals to specialist care and number of postnatal home visits. Differences in changes within the two groups before and after the intervention were compared by using mixed effect models.

Results 14 intervention clinics and 25 control clinics were included. Number of antenatal visits increased by 1.16 per woman in the intervention clinics, while declined by 0.39 in the control clinics, giving a statistically significant difference in change of 1.55 visits $(95 \% \mathrm{Cl} 0.90$ to 2.21$)$. A statistically significant difference in number of referrals was observed between the groups, giving a ratio of rate ratios of 3.65 (2.78-4.78) as number of referrals increased by a rate ratio of 3.87 in the intervention group, while in the control the rate ratio was only 1.06 . Home visits increased substantially in the intervention group but decreased in the control group, giving a ratio of RR 97.65 (45.20 - 210.96)

Conclusion The Palestinian midwife-led continuity model improved use and some quality indicators of maternal services. More research should be done to investigate if the model influenced individual health outcomes and satisfaction with care.

Trial registration number NCT03145571; Results.

\section{INTRODUCTION}

As a low/middle-income country under occupation, Palestine depends largely on foreign aid. ${ }^{1}$
Strengths and limitations of this study

The pragmatic approach strengthens the applicability to real-life settings.

- The high number of clusters and the robust cluster data strengthen the study.

- A randomised allocation of clusters was not possible because the implementation of the midwife-led continuity model started before the study was planned.

- The ministry implemented the programme in the clinics they found appropriate which could have led to bias.

The facility-based registry did not include data at individual level.

The Palestinian authority is responsible for Palestinian health services in the occupied territories of the West Bank and Gaza. In 2013, the Palestinian Ministry of Health registered 61405 births and a fertility rate of 4.0 per woman in the West Bank. ${ }^{2}$ Maternal health services were provided by the Palestinian government, and by private and non-governmental organisations. Less than $1 \%$ of the women give birth at home. Governmental facilities covered $45.6 \%$ of antenatal care in 2013. The Palestinian Multiple Indicator Cluster Survey from 2014 found that $66.4 \%$ of rural women gave birth in governmental hospitals. Of these $40.7 \%$ left hospital within 6 hours post partum, and $73 \%$ did not receive any additional postnatal care. ${ }^{3}$

In 2009, the Palestinian governmental maternal services were described as of poor quality due to concerns for being overcrowded and understaffed. Patients reported dissatisfaction with care as antenatal visits were short and lacking content. ${ }^{4}$ Overcrowded labour rooms prohibited women from bringing a birth companion. ${ }^{5}$ Midwives had restricted scope of practice and little autonomy and were not used by the Ministry 
as antenatal care providers. ${ }^{4}$ The clinics were not able to carry out postnatal home visits as required by governmental standards. ${ }^{6}$ Poor women were less likely to have postnatal care. ${ }^{7}$

Poverty, deprived infrastructure, military checkpoints and armed Israeli settlers restrict freedom of movement and reduce access to central health facilities and legal assistance in rural areas. ${ }^{8}$ During an escalation of the conflict between the years 2000 to 2006, it was reported that 69 women gave birth at military checkpoints, causing casualties in both mothers and babies, as they were not allowed to reach hospitals. ${ }^{4}$ Although the political situation in the West Bank was less volatile in the following decade, rural women are still vulnerable and depend more on governmental facilities than women in urban areas as rural private services are scarce. ${ }^{9}$

Several studies describe how midwife-led continuity models improved health for mothers and babies. Most studies were from high-income countries. ${ }^{10-16}$ The WHO recommends implementation and research on midwife-led continuity models to improve quality in low/ middle-income countries. ${ }^{17}$ Two main ways of organising such models are described in the literature. In the caseload model, one midwife cares for up to 45 women and facilitate relational continuity, while in the team midwifery model, a group of four to six midwives can provide care for up to 360 women through the pregnancy, intrapartum and postnatal period. Ideally, in both models, women during labour are cared for by a known midwife. ${ }^{11} 17$

To improve services in rural areas, the Palestinian Ministry of Health, in cooperation with the non-governmental humanitarian organisation Norwegian Aid Committee, launched the implementation of a modified midwife-led continuity, caseload model, in 2013, starting in the Nablus and Jericho Governmental hospitals and surrounding villages. The implementation involved the communities as well as several levels in the Ministry of Health to overcome known barriers to quality of care. ${ }^{18}$

The aim of this study was to investigate whether the Palestinian midwife-led continuity model had an impact on the use of maternity services and selected quality indicators at the two regions' clinics after 2 years of experience.

\section{METHODS \\ Implementation of the Palestinian midwife-led continuity model}

The modified caseload model aimed at establishing a relationship between the pregnant woman and her midwife during pregnancy and the postnatal period. The midwife also worked at the governmental hospital, where most women would give birth unless they chose a private hospital.

Once assigned, midwives in Nablus and Jericho governmental hospitals received training. Under supervision, they provided antenatal care in clinics and postnatal home visits in the surrounding villages. The hospital in Nablus had enough midwives to serve 10 villages per week, meaning two midwives would leave hospital each weekday, 5 days a week. Midwives from Jericho hospital served five villages in the Jordan Valley, with one midwife visiting one village every weekday. Three extra midwives were employed in the hospital in Nablus, and two in Jericho, to maintain the capacity at the labour ward. All midwives worked full time, as part time employment was not possible at the Ministry of Health. The same midwife visited the same village, usually once a week. If the designated midwife was on holiday or sick leave one of the other midwives would cover her village. The ideal case load per midwife was around 50 pregnant women yearly but should not exceed 100. Thus, the smallest village with 16 registered pregnant women per year was visited every second week only, and the largest village with 163 registered pregnant women was shared by two midwives weekly. The remaining working days the midwife spent in the labour ward. All pregnant women were informed that their midwife during pregnancy also worked at the local governmental hospital. Independent of place of delivery, all women registered at the clinic were to be offered postnatal home visits. All pregnant women were informed that the limited numbers of midwives and the large workload in the labour ward made it difficult to ensure they would meet the midwife they knew from antenatal care during labour. Women were given the phone number for their midwife in case of an emergency. The level of relational continuity was limited to the antenatal and postnatal period.

Nevertheless, a relational continuity was possible also during labour if their known midwife happened to be on duty. Implementing the model aimed to strengthen the relationship between the woman and her midwife, improve interdisciplinary cooperation and reduce the barrier between hospital and primary healthcare. The midwives received driving lessons to obtain a driving license and used designated cars with the Ministry of Health logo and marked Midwifery Care to facilitate transportation to villages and homes. Standard care in the clinics without this model was offered mainly by nurses or midwives and medical doctors (general practitioner) working only in primary healthcare.

\section{Study design}

As the implementation started before the study, a non-randomised intervention design was chosen to evaluate the model, based on registry data at cluster level from two complete years before (2011 and 2012) and two complete years after (2014 and 2015) the intervention. Clinics where the model was implemented were compared with clinics where the model was not implemented. Both arms of the study followed the same written governmental procedures.

The study was part of an implementation research project aiming at documenting the effect of the midwife-led continuity model. The study was approved by the Regional Ethical Committee of South East Norway and by the Palestinian Ministry of Health. 
Clinics (clusters) in the two regions $(n=53)$

total population: 528054

\section{Excluded: \\ Urban clinics $(n=8)$ \\ Clinics with incomplete intervention period $(n=3)$ Clinics established after intervention $(n=3)$}

Figure 1 Flow chart showing the stratification of all clusters in the study area.

\section{Clusters}

The clusters consisted of governmental primary health village clinics in Nablus and Jericho regions. There were 53 active clinics during the study period. During autumn 2013, the midwifery model was implemented in 16 clinics.

All clinics were stratified for inclusion by rural and urban location, activity period and intervention period.

\section{Exclusion criteria}

Clinics located less than $3 \mathrm{~km}$ from Nablus and Jericho centre were defined as urban, thus pregnant women had better access to private and non-governmental services. Clinics in urban areas were therefore excluded. Clinics opened during the study period were excluded due to incomplete data.

Clinics where the intervention was prematurely terminated or introduced later during the study period, were excluded because of contaminated data.

\section{Outcomes}

The number of antenatal visits was chosen as the primary outcome. Secondary outcomes were number of pregnant women referred to higher level of care and number of women receiving postnatal home visits. Other outcomes were number of women registered at the clinic for antenatal care, number of pregnant women referred for abnormal blood sugar levels, number of women seen by doctor after birth, number of newborns seen by doctor after birth and number of total postnatal consultations for mother and newborn.

\section{Statistical analysis}

Aggregated data were retrieved from the governmental registry. The registry consisted of anonymous data reported monthly from all clinics to the central statistical database in the Ministry of Health. The registry did not include data at an individual level.

Mean, SD and range were given for normally distributed and count variables. Percentage and total number were given for categorical variables.

Change from baseline in the intervention and standard care groups and any differences between the groups' changes were examined by using mixed effects models. In the mixed models, the clinic was specified as cluster (ie, random variable), time and group, and 


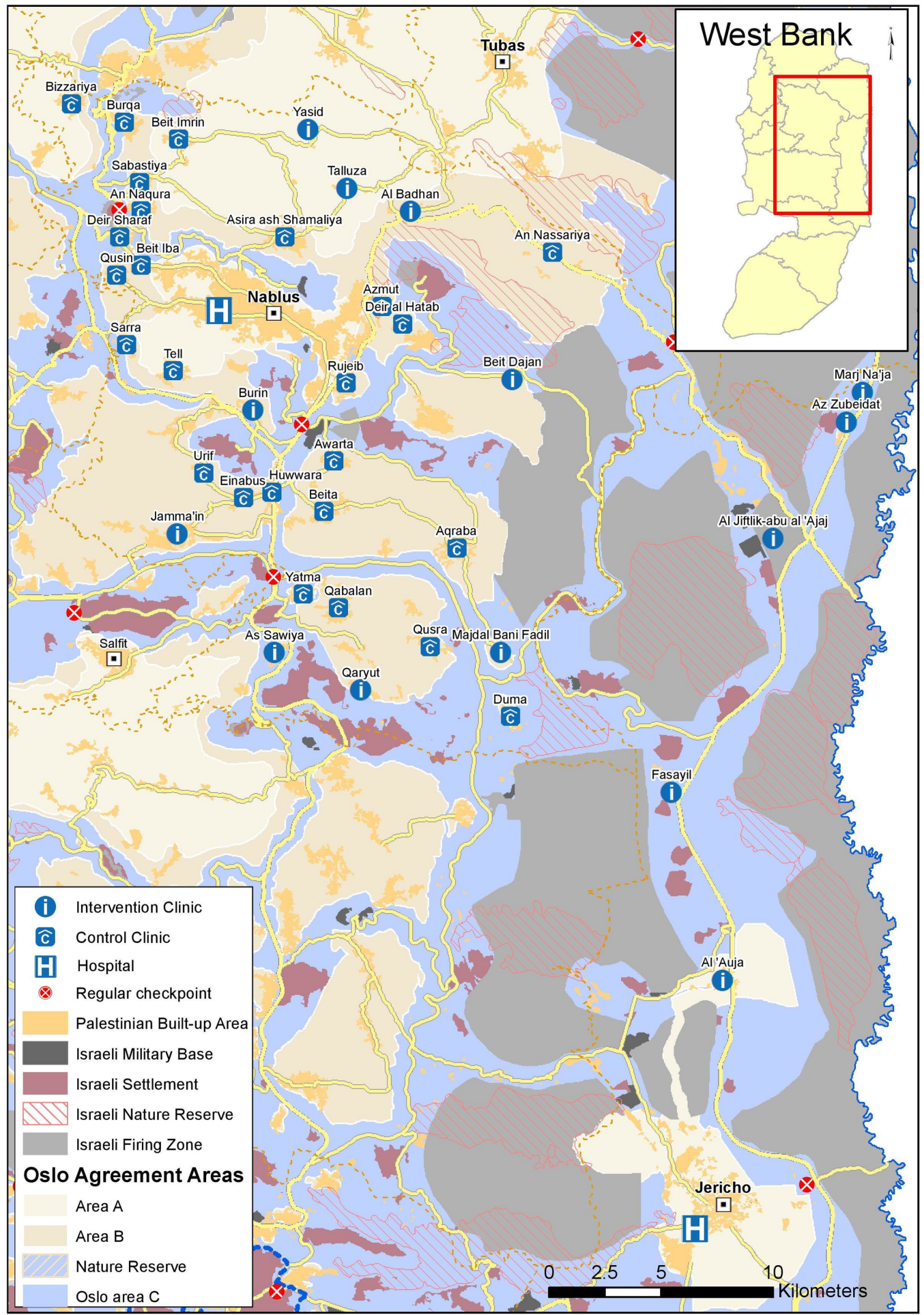

Figure 2 Map showing the location of all included clusters in the study area.

interaction between time and group were treated as fixed variables.

Approximately, normally distributed count outcomes were fitted by mixed effects linear regressions. Before fitting, the outcome variables were divided by the number of registered pregnant women, or newborns, to calculate average values. Variance weights for each average were then computed and included in a variance formula in the model because of heteroscedasticity, since the computed averages are based on different numbers of pregnant women.

Mixed effects Poisson regressions were used to fit non-normally distributed count outcomes, and an offset variable was used to adjust for the total number of (individual) registrations that were under risk in the models.

Measured confounding variables, which could have influenced the key estimates, were: the village's population size, whether the clinic had an employed community 
Table 1 Characteristics of clusters*

\begin{tabular}{llll}
\hline Characteristics & & Intervention & Control \\
\hline Population served & Mean & 3402 & 4636 \\
& Minimum/maximum & $1000 / 7554$ & $1875 / 11017$ \\
Distance to hospital (km) & Mean & 23 & 12.6 \\
& Minimum/maximum & $5 / 59$ & $3 / 28$ \\
$\begin{array}{l}\text { Number of clinics with employed community } \\
\text { midwife }\end{array}$ & 0 & 8 \\
$\begin{array}{l}\text { Number of clinics with laboratory } \\
\text { Additional clinics in village (NGO) }\end{array}$ & 5 & 10 \\
$\begin{array}{l}\text { Number of clinics with regular military check points between village and } \\
\text { hospital }\end{array}$ & 6 & 2 \\
\hline
\end{tabular}

*14 clinics with intervention and 25 clinics with standard care (control). NGO, non-governmental organisation.

midwife and laboratory equipment, regular military checkpoints between village and hospital and distance from hospital. These possible confounders were included in the mixed models for adjusting.

Adjusted regression coefficient as means and rate ratios (RRs) with 95\% CIs were given. Two-sided p values of less than 0.05 were considered statistically significant.

The map was developed by using ArcGIS software, and the attribute/database is part of the same application.

The analyses of mixed effect models were performed with R V.3.4 and STATA V.14. Descriptive analyses were carried out using IBM-SPSS V.21 for Windows.

\section{RESULTS}

After stratification, 39 clinics were included in the study: 14 as intervention and 25 as control clinics (figure 1).

In total, 10034 women booked at the 39 included clinics during the study period, 2784 in the intervention clinics and 7250 in the control clinics.

The clinic locations are presented in figure 2.

The Palestinian Ministry of Health confirmed that no other activities were introduced unequally to the groups during the study period. The clinics were located in a region where political unrest and economic hardship most likely would affect the intervention and control groups similarly during the study period. The measured possible confounders presented in table 1 were adjusted for in the final results; none had significant confounding effect.

Descriptive statistics of primary and secondary outcome variables such as number of individuals registered, mean, SD and range for the two time points in the intervention and standard care are presented in table 2 .

Change within the intervention and standard care group as means and RRs and difference between the changes within the two groups, controlled for potential confounding covariates are presented in table 3 .

\section{Antenatal use}

There was statistically significant difference in average change in mean number of antenatal visits between the groups by 1.55 (1.38-1.54), $\mathrm{p}=0.0004$. Mean number of visits increased by 1.16 visits with the new model, while standard care declined with -0.39 visits. In other words, clinics with the new model had an increase from 3.7 mean number of antenatal visits per pregnant woman before the model was introduced to 4.7 mean number of antenatal visits per woman after, while in the control clinics, mean number of antenatal visits per woman decreased from 4.6 to 4.2 visits.

\section{Referrals}

A statistically significant difference in change between the groups' number of referrals to a higher level of care was observed giving a ratio of RRs of 3.64 (2.78$4.78), p<0.0001$. For the intervention group, referrals increased by a RR 3.87, meaning that the number of referrals increased from $7.3 \%$ to $25.6 \%$ of all registered women in the clinics, while the control group only had a change RR 1.06, meaning that the percentage of referrals moved only from $12 \%$ to $12.8 \%$ during the study period.

\section{Postnatal service}

Postnatal home visits increased substantially at the intervention clinics, whereas at the control clinics it dropped giving a ratio of RRs 97.65 (45.20-210.96), $\mathrm{p}<0.0001$.

With women in the intervention group, mean number of postnatal contacts with health services increased significantly, whereas no increase was observed at clinics with standard care, giving a ratio of RRs of 0.60 (95\% CI 0.46 to 0.75 ) p $<0.0001$. Also, a significant increase in mean number of newborn's healthcare contacts were observed with the new model, but not in group with standard care, giving a ratio of RRs $0.33(0.16-0.52) \mathrm{p}=0.0004$. 
Table 2 Descriptive statistics for primary and secondary outcomes at baseline and 2 years after the implementation

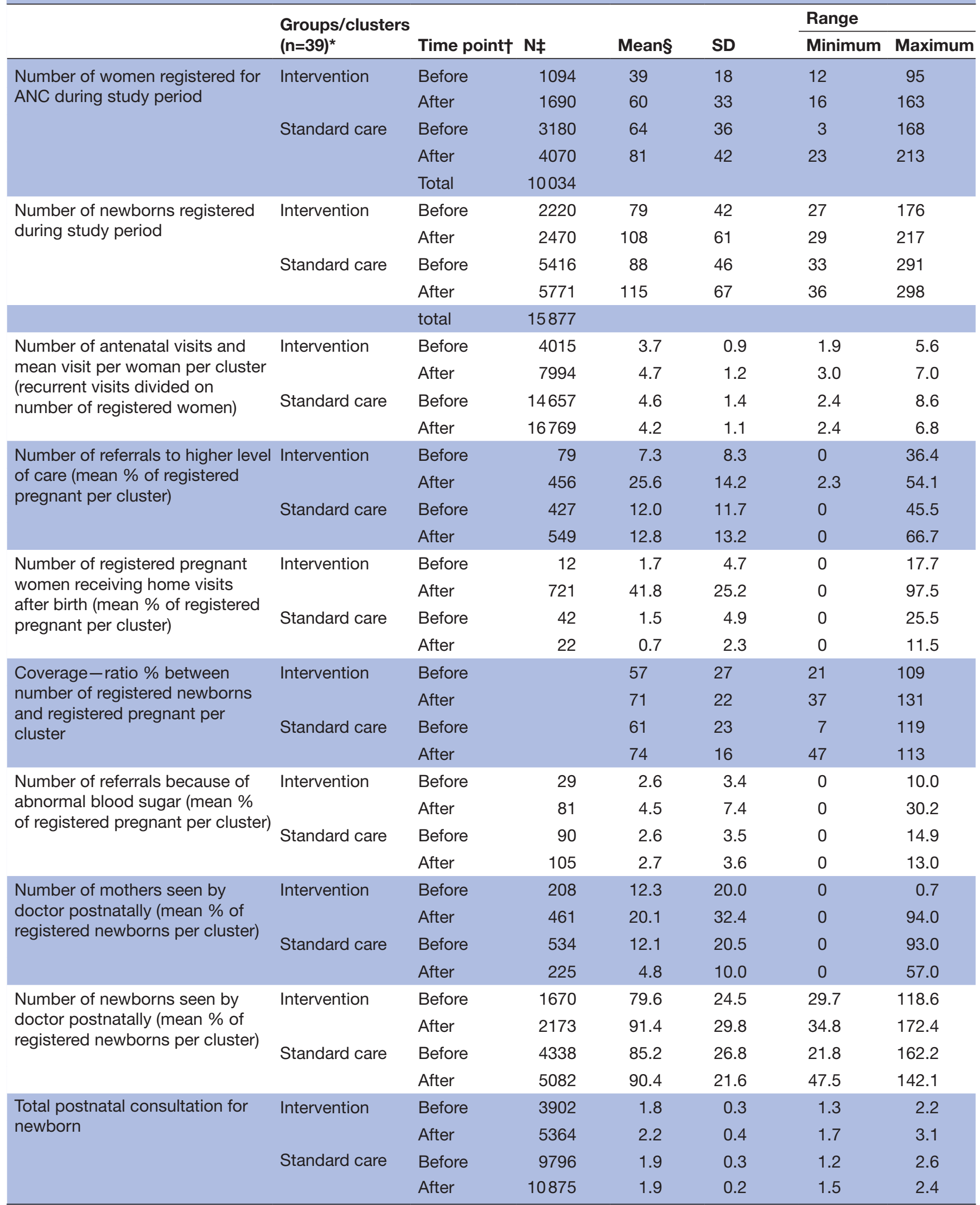

Continued 
Table 2 Continued

\begin{tabular}{|c|c|c|c|c|c|c|c|}
\hline & \multirow{2}{*}{$\begin{array}{l}\text { Groups/clusters } \\
(\mathrm{n}=39)^{\star}\end{array}$} & \multirow{2}{*}{ Time point† } & \multirow[b]{2}{*}{$\mathbf{N} \ddagger$} & \multirow[b]{2}{*}{ Mean§ } & \multirow[b]{2}{*}{ SD } & \multicolumn{2}{|l|}{ Range } \\
\hline & & & & & & Minimum & Maximum \\
\hline \multirow{3}{*}{$\begin{array}{l}\text { Total postnatal consultations for } \\
\text { mothers of registered newborn }\end{array}$} & Intervention & Before & 1830 & 0.9 & 0.4 & 0.2 & 1.7 \\
\hline & \multirow[t]{2}{*}{ Standard care } & Before & 5073 & 1.0 & 0.5 & 0.2 & 3.1 \\
\hline & & After & 5399 & 1.0 & 0.7 & 0.2 & 1.6 \\
\hline
\end{tabular}

*14 intervention clusters and 25 standard care clusters.

†Two years before intervention (2011 and 2012) and 2 years after intervention (2014 and 2015).

$\ddagger$ Number of total individual registrations.

$\S$ The mean at cluster level.

ANC, antenatal care.

\section{DISCUSSION}

In the clinics with the midwife-led continuity intervention, a significant rise in mean number of antenatal visits per woman was observed, whereas number of visits per woman decreased in the clinics with standard care during the same period. It is thus likely that the improved use was a result of the intervention. WHO recommended in $2002 \mathrm{a}$ minimum of four focused antenatal visits for healthy pregnant women. ${ }^{19}$ After evaluating new evidence, the recommendation was revised in 2016 to a minimum of eight antenatal visits to reduce perinatal mortality and improve women's satisfaction. ${ }^{171820}$ The women's increased adherence to service in clinics with midwife-led continuity may indicate that women experienced improved quality of

Table 3 Change before and after intervention in both groups and multiplicative difference of changes between the groups

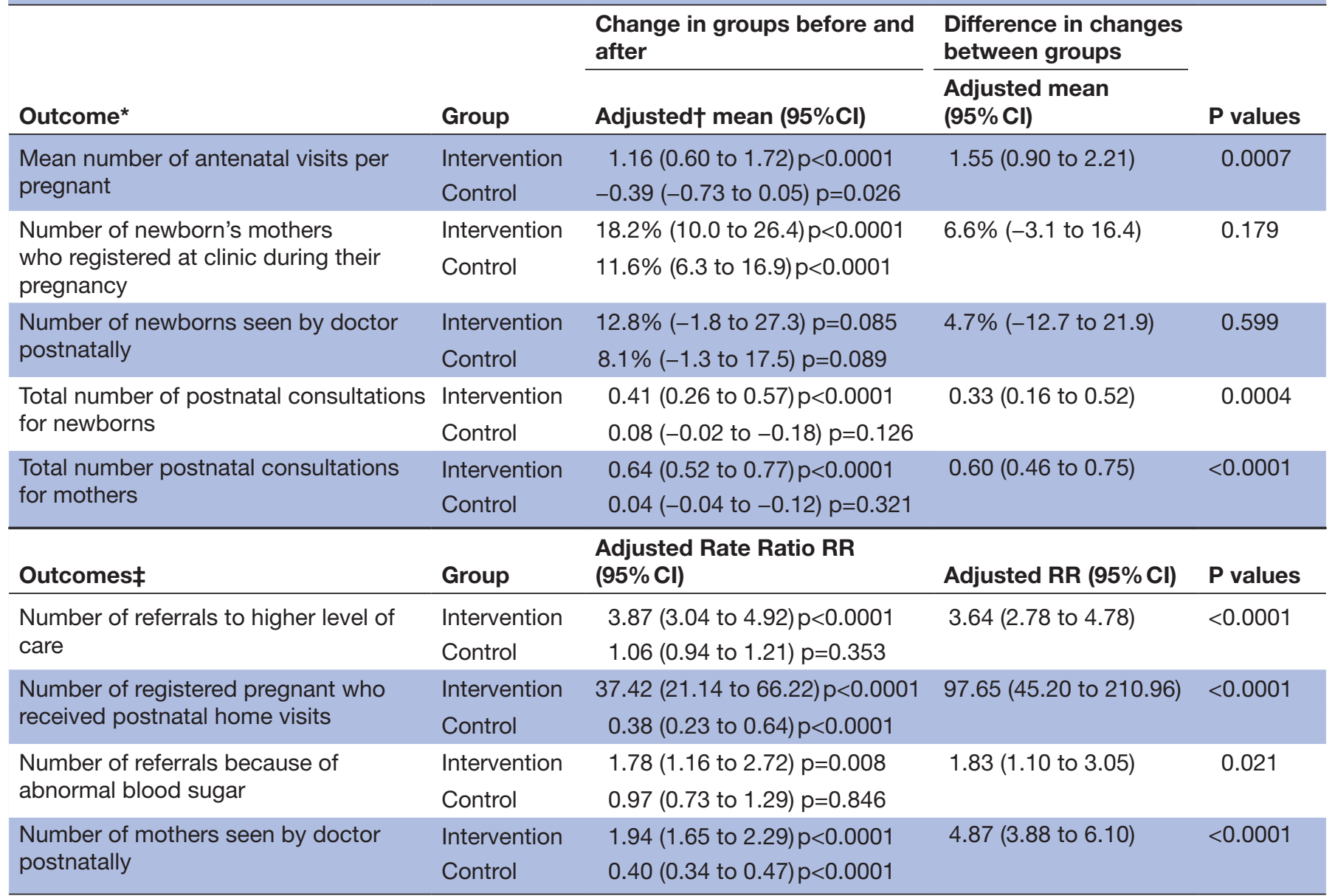

${ }^{*}$ Mixed effect linear regression was used to analyse change in and between clusters when data had normal distribution.

†All outputs were adjusted for potential confounders without any change in value. Covariates adjusted for were: distance from clinic to city hospital $(\mathrm{km})$, population in village, if there were additional clinic in village, clinics with community midwife, clinics with laboratory and clinics with a regular checkpoint on the way to hospital.

$\ddagger$ Mixed-effect Poisson regression was used to analyse the change in clusters when data was not normal distributed. 
the services. Relational continuity is an important tool to enhance communication and thus satisfaction with care. ${ }^{16}$ The association between improved quality of care and increased use is supported by several previous studies and by WHO recommendations to improve use and quality by introducing midwife-led continuity of care..$^{12} 141718$

It is a possibility that the pregnant woman would feel safe knowing that the midwife following her throughout pregnancy also worked at the public hospital where she would give birth, and that her midwife would visit her at home after birth. Due to the heavy workload, the midwives could not be on call to attend birth. Midwife-led continuity of care in settings with few midwife resources and heavy workload must balance the demands on the midwives. Although women were not guaranteed that the same midwife providing them antenatal and postnatal care would attend their labour, their midwife's connection to the governmental hospital might have reduced the alien barrier to the hospital and restored a feeling of security for the rural women.

A qualitative study investigated midwives' experience of working with a similar model in the Ramallah region from 2007 to 2011. The midwives described how the model enabled them to give individualised care and how the broader scope of practice and increased autonomy gave them important experience and tools for their work. ${ }^{21}$ This could serve to explain women's adherence to the antenatal service, because building a relationship with competent, respectful and motivated midwives probably increased their wish to return to receive more care.

In the intervention group, a change in referral mechanisms was observed. The midwives working with the new model identified significantly more risk factors leading to referral to higher level of care than in clinics with standard care. The finding of more women with abnormal blood sugar level indicates that the model improved the identification of important risk factors. The proportion of pregnant women referred to higher level of care increased to $25.6 \%$ with the new model versus $13 \%$ with standard care during the study period. The proportion in the new model is in line with the WHO estimate presented in guidelines from 2001, that in general $25 \%$ of pregnant women would need additional antenatal care due to health complications before or during pregnancy. ${ }^{22}$ The village clinics had little, if any, technical resources to investigate risk signs, so referral to higher level of care was necessary to follow-up any possible complications.

One important quality indicator of antenatal care is the ability to detect possible complications and involve specialist care when necessary. Kearns and Caglia demonstrate that improved referral networks are a key element for improving quality in low-resource settings. ${ }^{23}$ The process of information and referral within the system is also highlighted by the WHO framework as one core indicator of quality of services. ${ }^{24}{ }^{25}$ Some countries have much higher level of maternal health risks than others due to poverty, high fertility rate and general health challenges. ${ }^{106}$ A Palestinian study from 2015 revealed that
$26.9 \%$ of women who gave birth experienced one or more morbidities. ${ }^{27}$ The rise in numbers of referrals after introducing the new model matched the WHO and the local estimates. Thus, it seems reasonable to suggest that the intervention improved the referral system.

The results furthermore showed a substantial increase in the number of postnatal care contacts for mothers and newborns, including home visits. The WHO recommendation for postnatal care is a minimum of three postnatal contacts and a minimum of one home visit preferably during the first week after birth. ${ }^{28}$ The result from the study consequently indicates that the implementation of midwife-led continuity models may contribute to reach such a goal.

Filby et al describe how lack of transportation hamper quality improvements in other rural resource-constrained settings. ${ }^{29}$ The implementation in rural Palestine included a designated vehicle and driving skills for the midwives. Facilitation of transportation was consequently a key factor in reaching out to the villages and home visits.

The fact that women receiving midwife-led continuity were more frequently seen by a doctor in the clinic after birth $(20.1 \%$ vs $4.8 \%)$, in addition to the midwife, indicates improved interdisciplinary cooperation. When midwives undertook home visits and discovered health problems or risks, they involved the doctor. The findings also showed that there was a systematic check of newborn babies by doctors in all the village clinics, and the home visit from the midwife added to this. The increase in, and variation of, postnatal contacts including home visits, make it reasonable to conclude that the midwifery model improved both use and quality of postnatal care at a cluster level.

\section{Limitations of the study}

The study was carried out after the implementation of the midwife-led continuity model started. This prevented a randomised allocation of clinics to intervention and control clusters. The number of midwives available in the hospitals limited the number of clinics for implementation to a total of 15 in these regions. The Ministry chose to implement the programme in the clinics they found appropriate. The baseline data show that a reason for choosing these clinics were due to challenges in service provision, thus improvements could have been easier achieved and lead to bias.

Another limitation was weak data because the facility-based registry did not include data at individual level. This is a common problem in low/middle-income countries. ${ }^{23}$ Lack of an individual reproductive health registry prevented measuring individual impact and an intracluster coefficient. Thus, it was not possible to know when women registered at the clinic or who came back for recurrent antenatal visits or the reasons for referrals.

\section{Strength of the study and further recommendations}

The high number of clusters and the robust cluster data strengthen the study. The organisational leadership, 
engagement and adherence of the multidisciplinary team strengthen the sustainably of a complex intervention and its applicability to real-life settings. The findings make it reasonable to conclude that the new model had an effect on the use and on some quality indicators of the maternal services. The study can be a useful tool in power calculations and planning of randomised trials for future implementation of the model.

Triangulation of methods within an implementation research framework would be useful to investigate the broader effect of the implementation. This is highly recommended when introducing evidence-based interventions to improve health service delivery in real-world settings where context is an important factor. ${ }^{30}$ Further research should be done to investigate if the model could have an impact on individual health outcomes for mother and newborn and on satisfaction with care. Previous research has described midwife-led models as a cost-saving way to improve maternal health in developing countries. ${ }^{12} 31 \mathrm{~A}$ study of this model's cost-effectiveness would be useful. The general understaffing of both primary and secondary governmental health services should be taken into consideration. This calls for an increase in the number of midwives to improve quality. By implementing the model, more midwives were employed at the hospitals to serve the community, enhancing the workforce of trained midwives in both primary and secondary health service. The benefit of the midwife's broader scope of practice and experience and the improved interdisciplinary cooperation should be investigated. The cost of transportation was reduced to a minimum by enabling the midwives to drive the vehicle themselves, as employing drivers would have added unsustainable cost to the model.

\section{CONCLUSION}

The findings make it reasonable to conclude that the new model had an effect on the use and on some quality indicators of the maternal service.

The positive change in facility-level outcomes show that clinics with the midwifery model in the regions of Nablus and Jericho improved services during pregnancy and during postnatal period. The findings indicate the improvement of use and some quality indicators linked to facility-level outcomes, such as continuity, functioning referral system and postnatal home visits.

The results of this study support the expansion of the model to new areas in Palestine. We believe the model can be useful for other low/middle-income countries to improve use and quality of care.

Acknowledgements The authors would like to thank the Palestinian Ministry of Health for their efforts in implementing the model and preparing and sharing of their health registry. We would also like to thank the Norwegian Aid Committee (NORWAC) for supporting the study and United Nations Office for the coordination of Humanitarian Affairs (OCHA) for developing the map. Finally, we are grateful to all the involved Palestinian midwives for their courageous efforts in improving care for women in Palestine.
Contributors BM was involved in the implementation, study design, datacollection, data analysis, data interpretation and writing and drafted the article, figures and tables. MiL was involved in study design, datainterpretation and writing. LMD was involved with study design, data analysisand writing. MaL was involved in study design, data interpretation and writing. AAA with the implementation, data interpretation and writing. MS conducted collection and systematisation of data. EF was involved in study design, datacollection, data analysis, data interpretation and writing. All authors have reviewed and approved the final manuscript.

Funding This work was partly supported by the Research Council of Norway through the Global Health and Vaccination Program (GLOBVAC), project number 243706 and partly by public funding through Norwegian Aid Committee(NORWAC). Three of the authors were partly employed by NORWAC and were involved in the implementation and interpretation of data. The analysis was performed by a statistician at Oslo University Hospital. The corresponding author had full access to all the data in the study and had final responsibility for the decision to submit for publication.

Competing interests None declared.

Patient consent Not required.

Ethics approval The study was approved by the Norwegian Regional Committee for Medical Health Research Ethics South East (REK) id number: 2015/1235. It was also approved by the Palestinian Ministry of Health.

Provenance and peer review Not commissioned; externally peer reviewed.

Data sharing statement The data file is available upon request to the corresponding author after receiving approval from the Palestinian Ministry of Health.

Open Access This is an Open Access article distributed in accordance with the Creative Commons Attribution Non Commercial (CC BY-NC 4.0) license, which permits others to distribute, remix, adapt, build upon this work non-commercially, and license their derivative works on different terms, provided the original work is properly cited and the use is non-commercial. See: http://creativecommons.org/ licenses/by-nc/4.0/

(C) Article author(s) (or their employer(s) unless otherwise stated in the text of the article) 2018. All rights reserved. No commercial use is permitted unless otherwise expressly granted.

\section{REFERENCES}

1. World Bank. Country information. http://data.worldbank.org/country/ west-bank-and-gaza (accessed Sep 2017).

2. Palestine Ministry of Health. Palestine Ministry of Health Annual Report 2013. Palestine, Nablus, 2013.

3. Palestinian Central Bureau of Statistics. Palestinian Multiple Indicator Cluster Survey 2014, Final Report. Ramallah, Palestine, 2015.

4. Rahim HF, Wick L, Halileh S, et al. Maternal and child health in the occupied Palestinian territory. Lancet 2009;373:967-77.

5. Wick L, Mikki N, Giacaman R, et al. Childbirth in Palestine. Int $J$ Gynaecol Obstet 2005;89:174-8.

6. Abu Awad A. Dissertation, implementation of postnatal protocols by nurse in primary health care clinics in the West Bank: University of Wisconsin-Madison, 2011.

7. Nabaa HAA, Hilal GA, Sbeih SA, et al. Access to care for women reporting postnatal complications in the occupied Palestinian territory: a cross-sectional study. The Lancet 2013;382:S2.

8. Reem Al-Botmeh U. A review of Palestinian legislation from a women's right perspective: UNDP, 2012. UNDP-papp-researchLegislative english.pdf

9. United Nations. Office for the coordination of humanitarian affairs occupied Palestinian territory area c vulnerability profile. http://data. ochaopt.org/vpp.aspx (accessed Sep 2017).

10. Graham W, Woodd S, Byass P, et al. Diversity and divergence: the dynamic burden of poor maternal health. Lancet 2016;388:2164-75.

11. Homer C, Brodie P, Leap N. Midwifery continuity of care: a practical guide. Sydney, New York: Churchill Livingstone/Elsevier, 2008.

12. Sandall J, Soltani H, Gates S, et al. Midwife-led continuity models versus other models of care for childbearing women. Cochrane Database Syst Rev 2016;4:CD004667.

13. ten Hoope-Bender P, de Bernis L, Campbell J, et al. Improvement of maternal and newborn health through midwifery. The Lancet 2014;384:1226-35.

14. Renfrew MJ, McFadden $\mathrm{A}$, Bastos $\mathrm{MH}$, et al. Midwifery and quality care: findings from a new evidence-informed framework for maternal and newborn care. Lancet 2014;384:1129-45. 
15. Homer CSE, Friberg IK, Dias MAB, et al. The projected effect of scaling up midwifery. Lancet 2014;384:1146-57.

16. Homer CSE. Challenging midwifery care, challenging midwives and challenging the system. Women and Birth 2006;19:79-83.

17. World Health Organization. WHO recommendations on antenatal care for a positive pregnancy experience. 2016:152 http://apps.who. int/iris/bitstream/10665/250796/1/9789241549912-eng.pdf?ua=1

18. Nair M, Yoshida S, Lambrechts $\mathrm{T}$, et al. Facilitators and barriers to quality of care in maternal, newborn and child health: a global situational analysis through metareview. BMJ Open 2014;4:e004749.

19. Carroli G, Villar J, Piaggio G, et al. WHO systematic review of randomised controlled trials of routine antenatal care. The Lancet 2001;357:1565-70.

20. Dowswell T, Carroli G, Duley L, et al. Alternative versus standard packages of antenatal care for low-risk pregnancy. Cochrane Database Syst Rev 2015;7:CD000934.

21. Mortensen B. To be weiled or not to be: what unite is the question, experiences from a continuity of midwifery care model in Palestine and Norway. Bodø, Norway: Nord University, 2011:121.

22. BP VJ. Antenatal care randomized trial: manual for the implementation of the new model: UNDP, UNFPA, WHO, World Bank Special Programme of Research Development and Research in Human Reproduction, 2002. http://apps.who.int/iris/bitstream/ 10665/42513/1/WHO_RHR_01.30.pdf

23. Kearns AD, Caglia JM, Ten Hoope-Bender P, et al. Antenatal and postnatal care: a review of innovative models for improving availability, accessibility, acceptability and quality of services in lowresource settings. BJOG 2016;123:540-8.
24. World Health Organisation. Standards for improving quality of maternal and newborn care in health facilities. Geneva: WHO, 2016. http://apps.who.int/iris/bitstream/10665/249155/1/9789241511216eng.pdf?ua $=1$

25. Tunçalp Ö, Were WM, MacLennan C, et al. Quality of care for pregnant women and newborns-the WHO vision. BJOG 2015;122:1045-9.

26. Oyibo PG, Ebeigbe PN, Nwonwu EU. Assessment of the risk status of pregnant women presenting for antenatal care in a rural health facility in Ebonyi State, South Eastern Nigeria. N Am J Med Sci 2011;3:424-7.

27. Hassan SJ, Wick L, DeJong J. A glance into the hidden burden of maternal morbidity and patterns of management in a Palestinian governmental referral hospital. Women Birth 2015;28:e148-e156.

28. World Health Organisation. Recommendations of postnatal care for mothers and new born, 2013 the departments of maternal, newborn, child and adolescent health and reproductive health and research of the World Health Organization. 2013:62 http://apps.who.int/iris/ bitstream/10665/97603/1/9789241506649_eng.pdf?ua=1

29. Filby A, McConville F, Portela A. What prevents quality midwifery care? A systematic mapping of barriers in low and middle income countries from the provider perspective. PLoS One 2016;11:e0153391.

30. Peters DH, Adam T, Alonge O, et al. Implementation research: what it is and how to do it. BMJ 2013;347:f6753.

31. Friedman HS, Liang M, Banks JL. Measuring the cost-effectiveness of midwife-led versus physician-led intrapartum teams in developing countries. Womens Health 2015;11:553-64. 